\title{
A Serum Factor that Recalcifies Demineralized Bone Is Conserved in Bony Fish and Sharks but Is Not Found in Invertebrates
}

\author{
N. J. Hamlin, K. G. Ong, P. A. Price \\ Division of Biological Sciences, University of California-San Diego, La Jolla, CA 92093-0368, USA
}

Received: 18 August 2005 / Accepted: 14 February 2006 / Online publication: 9 May 2006

\begin{abstract}
We investigated the evolutionary origin of a serum activity that induces calcification within a type I collagen matrix, an activity previously described in rat and bovine serum. Serum was obtained from vertebrates with calcified tissues (bony fish and shark), vertebrates without calcified tissues (lamprey and hagfish), and three invertebrates (marine worm, crab, and sea urchin). Serum from the bony fish and shark proved to contain a potent nucleator of collagen calcification; like the previously described calcifying activity in rat serum, the fish and shark activities are both able to recalcify a demineralized rat tibia when tested in Dulbecco's modified Eagle medium containing as little as $1.5 \%$ of the respective serum and have an apparent molecular weight of 50-150 kDa. No calcifying activity could be detected in any of several experimental tests of invertebrate or hagfish serum. Weak calcifying activity could be detected in lamprey serum, but calcification was restricted to the growth plate of the decalcified tibia, with no detectable calcification in the type I collagen of the midshaft. These studies reveal a correlation between the evolutionary timing of the appearance of calcified tissues in vertebrates and the appearance of the serum activity that initiates calcification within collagen and, therefore, support the hypothesis that this serum activity may play a role in normal calcification of bone.
\end{abstract}

Key words: Calcification of bone - Serum nucleator Evolutionary conservation — Bony fish - Cartilaginous fish

We recently showed that the type I collagen matrix of demineralized bone recalcifies when incubated in rat or bovine serum for 6 days at $37^{\circ} \mathrm{C}[1,2]$. The incorporation of calcium and phosphate into demineralized rat tibias ceases after several weeks of incubation in successive volumes of serum, and the amount of calcium and phosphate introduced into the demineralized tibias at this point is comparable to that present in the same bone segment prior to demineralization [2]. These fully recalcified tibias are palpably hard, radiographs of the recalcified tibias are indistinguishable from tibias prior

Correspondence to: P. A. Price; E-mail: pprice@ucsd.edu to demineralization, and the recalcified bone mineral is comparable to the original bone mineral in calcium and phosphate ratio and in Fourier transform infrared ratio (FTIR) and X-ray diffraction (XRD) spectra [2]. Early stages of bone recalcification in serum are characterized by the presence of numerous discrete foci of von Kossa staining, each $0.2-2 \mu \mathrm{m}$ in diameter, which are present throughout the collagenous matrix of the demineralized bone. An identical pattern of calcification is seen when rat tail tendon is incubated for 6 days in serum [1, 2], which shows that serum-induced calcification occurs in a type I collagen matrix that normally calcifies (demineralized bone) as well as in a type I collagen matrix that does not normally calcify in the rat (tendon).

These studies further showed that the recalcification of demineralized bone during incubation in serum is attributable to the presence of a serum calcification factor (or factors) that is sufficiently potent that it can initiate the recalcification of demineralized bone in Dulbecco's modified Eagle medium (DMEM) that contains only $1.5 \%$ serum $[1,2]$. Biochemical studies showed that this putative serum calcification factor(s) has an apparent gel filtration molecular weight of 55$150 \mathrm{kDa}$ and is inactivated by trypsin or chymotrypsin [2]. These observations show that the putative serum calcification factor that initiates the deposition of mineral within the collagen matrices of tendon and demineralized bone consists of one or more serum proteins with apparent molecular weights of 55-150 kDa.

To determine whether this serum nucleator is evolutionarily conserved across species, we investigated whether a similar calcification factor is found in nonmammalian vertebrates, in organisms with only calcium carbonate-containing structures, or in organisms that lack any calcified structures. To this end, we used methods developed to characterize the serum nucleator found in rat and bovine serum in order to determine whether a similar calcification factor is also found in serum from the following organisms: a bony fish of the class Osteichthyes, the hybrid striped bass (Morone 
saxatilis $\times M$. chrysops); a cartilaginous fish of the class Chondrichthyes, the leopard shark (Triakis semifasciata); two members of the jawless vertebrate class Agnatha, the Pacific hagfish (Eptatretus stoutii) and the Pacific lamprey (Lampetra tridentata); a marine worm of the phylum Echiura, the innkeeper worm (Urechis caupo); and two calcium carbonate-containing organisms, one of the phylum Arthropoda, the sheep crab (Loxorhynchus grandis), and one of the phylum Echinodermata, the red sea urchin (Strongylocentrotus franciscanus).

\section{Materials and Methods}

\section{Materials}

DMEM and penicillin-streptomycin were purchased from Invitrogen (Carlsbad, CA), and sodium azide was purchased from EM Science (Gibbstown, NJ). DMEM was supplemented with $1 \%$ penicillin-streptomycin and $0.02 \%$ sodium azide to prevent bacterial growth. The phosphate concentration of DMEM was increased from the basal $0.9 \mathrm{mM}$ to a final $2 \mathrm{mM}$, as described [1,2]. Sephacryl S-100HR gel filtration medium was from Amersham (Piscataway, NJ), and 3,500 and 50,000 high molecular weight cut-off (MWCO) dialysis tubing was from Spectrum Laboratories (Rancho Dominguez, CA). Bis-Tris polyacrylamide gels (4-12\%) were from Invitrogen. Newborn rat tibias were demineralized in $0.5 \mathrm{M}$ ethylenediaminetetraacetic acid (EDTA) and washed exhaustively with ultrapure water as described previously [1, 2].

\section{Animal Sera Collection}

All animal experiments were approved by the UCSD Animal Subjects Committee. Male albino rats (Sprague-Dawley, 40-44 days old) were purchased from Charles River (Wilmington, MA) and exsanguinated under isoflurane anesthetic. Blood was allowed to clot for 30 minutes at room temperature and centrifuged at $1,400 \mathrm{~g}$ for 10 minutes in a clinical centrifuge to remove the clot and cellular components. Serum in $1 \mathrm{~mL}$ aliquots was quick-frozen on dry ice and stored at $-70^{\circ} \mathrm{C}$ until use.

Fresh adult hybrid striped bass (M. saxatilis $\times M$. chrysops $)$ blood was generously provided by Kent SeaTech (San Diego, CA). Upon collection of blood, serum was obtained and stored as described above for rat serum.

Leopard sharks ( $T$. semifasciata) and a blue shark (Prionace glauca) were caught off the coast of San Diego and housed at the Scripps Institute of Oceanography (SIO) Experimental Lab (La Jolla, CA). Blood was collected from donor sharks by caudal tail vein puncture, allowed to clot on wet ice for 2-3 hours, and spun in a clinical centrifuge for 10 minutes. Serum was pooled according to species and stored in $1 \mathrm{~mL}$ aliquots at $-70^{\circ} \mathrm{C}$.

Pacific lamprey (La. tridentata) serum was generously provided by Dr. Matthew G. Mesa (U.S. Geological Survey, Columbia River Research Laboratory, Cook, WA) and by David Close from Dr. Wei Ming Li's laboratory (Michigan State University, East Lansing, MI).

Pacific hagfish (E. stoutii) were caught off the coast of San Diego and housed at the SIO Experimental Lab. Hagfish were anesthetized with $100 \mathrm{mg} / \mathrm{L}$ ethyl 3-aminobenzoate, methanesulfonic acid (MS-222; Sigma, St. Louis, MO) in seawater. The fish were decapitated, and blood was collected by vertically suspending the animals. Blood was allowed to clot on wet ice for 2 hours, then spun; serum was collected and stored as described above.
Serum from marine innkeeper worms (U. caupo) was generously provided by Dr. Meredith Gould (University of California-San Diego). Serum was aliquotted and stored as above.

A sheep crab (Lo. grandis) was caught off the coast of San Diego and housed at the SIO Experimental Lab. Hemolymph $(80 \mathrm{~mL})$ was collected by heart puncture with large-bore needles and $10 \mathrm{~mL}$ syringes. Blood was allowed to clot for 3 hours on wet ice and then spun at $3,000 \mathrm{~g}$ for 1 hour at $4^{\circ} \mathrm{C}$ to collect serum. Aliquots $(1 \mathrm{~mL})$ of serum were frozen and stored as above.

Red sea urchins (S. franciscanus) found off the coast of San Diego were housed at the SIO Experimental Lab. Coelomic fluid was removed from donor sea urchins by gentle puncture of the peristomial membrane with a small-bore needle and syringe. A total of about $11 \mathrm{~mL}$ of fluid was pooled from two urchins. Clotting was allowed to occur for about 3 hours on wet ice, and then the fluid was centrifuged for 10 minutes in a clinical centrifuge to remove coelomic cells and any clot. Aliquots of serum were stored as above.

\section{Assay for Calcification}

The calcification assay used in these studies was described previously $[1,2]$. The DMEM diluent was boosted to $2 \mathrm{mM}$ phosphate in order to make the final ion product $([\mathrm{Ca}] \times$ $[\mathrm{Pi}]=3.6 \mathrm{mM}^{2}$ ) comparable to the average ion product in normal mammalian serum. Typical calcification solutions consist of neat serum or of different amounts of serum diluted into DMEM and fractions from a Sephacryl S-100 gel filtration column equilibrated with DMEM; the control solution was DMEM alone. Aliquots of calcification solution $(1 \mathrm{~mL})$ were placed into separate wells of a 24-well culture dish and preequilibrated for 1 hour at $37^{\circ} \mathrm{C}$ and $5 \% \mathrm{CO}_{2}$. A single demineralized newborn rat tibia was then added to each well and incubated for an additional 6-12 days.

To detect the presence of calcium phosphate-containing mineral, tibias were placed in $10 \mathrm{~mL}$ of $0.5 \%$ potassium hydroxide $(\mathrm{KOH})$ containing $0.002 \%$ alizarin red $\mathrm{S}$ (Sigma) for 24 hours with end-over-end mixing. Tibias were then rinsed with $0.05 \% \mathrm{KOH}$ and photographed. Each tibia was then placed in $1 \mathrm{~mL}$ of $150 \mathrm{mM} \mathrm{HCl}$ for 1 day at room temperature to extract mineral. Tibia extracts were quantitatively assayed for calcium by a colorimetric assay (JAS Diagnostics, Miami, FL). Quantitative phosphate determination was done by a colorimetric assay, as described [3].

It should be noted that demineralized newborn rat tibias differ somewhat in size and that this difference could contribute to differences in calcium and phosphate accumulation seen using this assay. One measure of this size difference is the amount of calcifiable type I collagen matrix present in the demineralized tibias, a number which should be proportional to the amount of mineral found in the tibias prior to demineralization; analysis of the left tibias from 10 randomly selected, nondemineralized newborn rat pups showed that there was $4.1 \pm 0.5 \mu \mathrm{mol}$ mineral phosphate per tibia $[$ mean \pm standard deviation (SD)].

\section{Sephacryl S-100 Gel Filtration Chromatography}

To characterize the molecular mass of the nucleator activity in serum, $1 \mathrm{~mL}$ samples of bony fish (teleost), shark, lamprey, hagfish, marine worm, crab, and sea urchin sera were fractionated over a $25 \mathrm{~mL}$ pipette column containing Sephacryl S-100HR gel filtration medium, as described previously [2]. DMEM containing $2 \mathrm{mM}$ phosphate was used as the column buffer, and the buffer reservoir was flushed with $5 \%$ $\mathrm{CO}_{2}$ to maintain $\mathrm{pH}$. The absorbance at $280 \mathrm{~nm}$ was determined for each $1 \mathrm{~mL}$ fraction, small aliquots of each fraction were set aside for electrophoresis, and each fraction was then placed into separate wells of a 24-well tissue culture plate. A single demineralized newborn rat tibia was added to each well and incubated at $37^{\circ} \mathrm{C}$ and $5 \% \mathrm{CO}_{2}$ for 6 (bony fish) to 12 
Table 1. Total calcium and ionic phosphate in serum before and after dialysis

\begin{tabular}{|c|c|c|c|c|}
\hline \multirow[b]{2}{*}{ Serum type } & \multicolumn{2}{|l|}{ Before dialysis } & \multicolumn{2}{|l|}{ After dialysis } \\
\hline & {$[\mathrm{Ca}]$} & {$\left[\mathrm{PO}_{4}\right]$} & {$[\mathrm{Ca}]$} & {$\left[\mathrm{PO}_{4}\right]$} \\
\hline Rat & $2.59 \pm 0.17$ & $3.33 \pm 0.16$ & $2.72 \pm 0.12$ & $2.08 \pm 0.28$ \\
\hline Bony fish & $2.75 \pm 0.21$ & $4.09 \pm 0.24$ & $2.50 \pm 0.16$ & $1.81 \pm 0.05$ \\
\hline Lamprey & $1.60 \pm 0.04$ & $1.46 \pm 0.08$ & $2.19 \pm 0.06$ & $2.08 \pm 0.07$ \\
\hline Marine worm & $9.53 \pm 0.20$ & $0.30 \pm 0.07$ & $1.76 \pm 0.01$ & $1.96 \pm 0.23$ \\
\hline Sheep crab & $10.29 \pm 0.08$ & $0.46 \pm 0.04$ & $1.89 \pm 0.07$ & $2.00 \pm 0.10$ \\
\hline Sea urchin & $9.04 \pm 0.34$ & $0.19 \pm 0.07$ & $1.75 \pm 0.07$ & $1.86 \pm 0.12$ \\
\hline
\end{tabular}

Serum samples were dialyzed for 2 days in 3,500 MWCO dialysis tubing vs. DMEM ([Pi $]=2 \mathrm{mM})$; total calcium and inorganic phosphate levels in serum before and after dialysis were measured colorimetrically as described in Materials and Methods. Values $(\mathrm{mM} \pm 1 \mathrm{SD})$ are from three independent measures

(shark) days. To determine the apparent molecular weight of serum proteins that coeluted with the serum calcification activity in this experiment, $2 \mu \mathrm{L}$ aliquots of protein-containing fractions were electrophoresed on a $4-12 \%$ sodium dodecyl sulfate (SDS) Bis-Tris polyacrylamide gel and stained with Coomassie brilliant blue. Protein sequencing of the prominent high molecular weight band in fraction 11 of shark serum was carried out on bands transferred from the polyacrylamide gel to a polyvinylidene difluoride membrane using a Procise 494 Sequencer (ABI Division, PE Biosystems, Foster City, CA).

\section{Dialysis of Serum with MWCO Membrane}

To confirm the higher molecular weight of the serum calcifying activity, $1.5 \mathrm{~mL}$ aliquots of rat and bony fish serum were each dialyzed using 50,000 MWCO tubing with a flat width of 12 $\mathrm{mm}$. Each dialysis sac was placed in a $50 \mathrm{~mL}$ conical tube containing DMEM ([Pi $]=2 \mathrm{mM})$ with the caps partially unscrewed and incubated at $37^{\circ} \mathrm{C}$ and $5 \% \mathrm{CO}_{2}$. The dialysis solution was changed three times over the 2 days of dialysis. Serum samples were removed from the sacs, and absorbance was measured at $280 \mathrm{~nm}$ to confirm there was no significant loss of protein. Calcification activity was evaluated by incubating a demineralized newborn rat tibia for 12 days at $37^{\circ} \mathrm{C}$ in a $1 \mathrm{~mL}$ volume of dialyzed serum or in a $1 \mathrm{~mL}$ volume of DMEM containing $10 \%$ dialyzed serum.

\section{Dialysis to Normalize Calcium and Phosphate between Serum Samples}

To normalize serum calcium and phosphate between invertebrates and vertebrates, samples were dialyzed against DMEM using a 3,500 MWCO membrane. Since the high level of calcium found in invertebrate serum $(\sim 10 \mathrm{mM}$, see Table 1$)$ might form a mineral precipitate with the $2 \mathrm{mM} \mathrm{PO}_{4}$ found in phosphate-boosted DMEM, invertebrate serum was dialyzed against normal DMEM $(\mathrm{Pi}=0.9 \mathrm{mM})$ for the first half-day, then dialyzed against phosphate-boosted DMEM.

\section{Results}

\section{Calcification Activity in Bony Fish (Teleost) Serum}

To test whether bony fish serum has nucleator activity, pooled serum samples from hybrid striped bass were diluted to $15 \%$ and $1.5 \%$ in DMEM ([Pi] $=2 \mathrm{mM})$ in a final volume of $1 \mathrm{~mL}$ and incubated with a demineralized newborn rat tibia for 6 days at $37^{\circ} \mathrm{C}$ and $5 \% \mathrm{CO}_{2}$, using procedures previously employed for bovine and rat serum $[1,2]$. Figure 1 shows representative alizarin- stained tibias and the calcium and phosphate levels in each tibia. Note the dark alizarin staining in the midshaft of each tibia and absence of staining in the cartilaginous ends, the same pattern of calcification seen in the original tibia prior to demineralization $[1,2]$. In agreement with previous studies [1, 2], control tibias incubated in DMEM ([Pi] $=2 \mathrm{mM})$ did not stain with alizarin and, when acid-extracted and analyzed for mineral, had minor amounts of calcium and no phosphate incorporated into the bone matrix (data not shown). These experiments were done three times with comparable results. Demineralized tibias also calcified when incubated in bony fish serum itself for 6 days at $37^{\circ} \mathrm{C}$ (data not shown), a result also seen with neat bovine and rat serum $[1,2]$.

To determine whether the molecular mass of the nucleator activity in bony fish serum is similar to that in rat serum, a $1 \mathrm{~mL}$ aliquot of fish serum was chromatographed over a Sephacryl S-100 HR column equilibrated with DMEM $([\mathrm{Pi}]=2 \mathrm{mM})$ using procedures previously employed for rat serum [2]. To assay for calcification activity, fractions were transferred to wells of a 24-well plate and incubated with a demineralized newborn rat tibia for 6 days at $37^{\circ} \mathrm{C}$ and $5 \% \mathrm{CO}_{2}$. Tibias were stained for calcification with alizarin red, then extracted with acid and assayed for calcium and phosphate. As seen in Figure 1, demineralized tibias recalcified when incubated in fractions 10 and 11 but not when incubated in the other protein-containing fractions or in the DMEM column buffer alone (not shown). To see if the calcification activity found in fractions 10 and 11 could be due to elevated calcium phosphate ion product in these fractions, ionic calcium and phosphate were measured in the protein-containing fractions. This analysis showed that all protein-containing fractions had ionic calcium and phosphate values identical to the values found in the DMEM column buffer (as anticipated from the mechanism of gel filtration). To examine what proteins elute in fractions 11 and $12,2 \mu \mathrm{L}$ of each fraction were electrophoresed on a $4-12 \%$ Bis-Tris polyacrylamide gel and stained with Coomassie brilliant blue (Fig. 2). Note that fractions 10 and 11 contain 


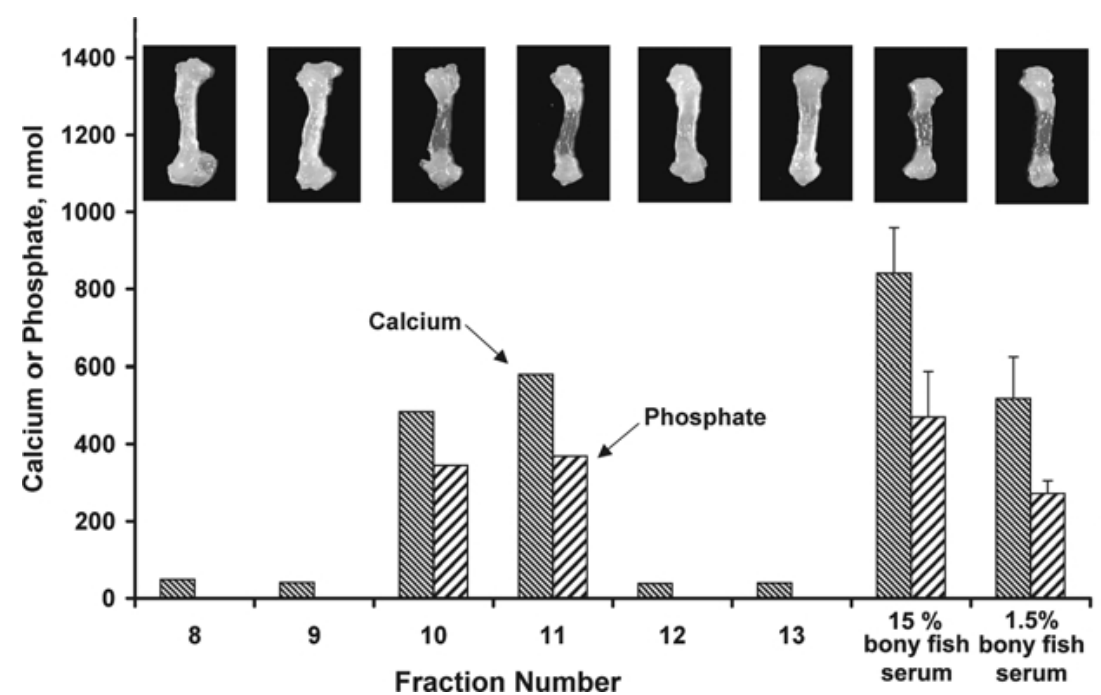

Fig. 1. Serum nucleator activity in Sephacryl S-100 column fractions of bony fish serum and in dilutions of this serum in DMEM. Hybrid striped bass serum was either diluted into DMEM at $15 \%$ or $1.5 \%$ in $1 \mathrm{~mL}$ volumes $(n=3)$ or run over a Sephacryl S-100 column with $1 \mathrm{~mL}$ fractions collected (see Materials and Methods). A demineralized newborn rat tibia was incubated in each of these dilutions or fractions for 6 days at $37^{\circ} \mathrm{C}, 5 \% \mathrm{CO}_{2}$. Photographs at the top show alizarin redstained tibias after the 6-day incubation. Only tibias from fractions 10 and 11 stained positive, as well as tibias in dilutions of bony fish serum at $15 \%$ and $1.5 \%$. The same tibias were extracted with $1 \mathrm{~mL}$ of $150 \mathrm{mM} \mathrm{HCl}$ and assayed for calcium and phosphate. Bars indicate the level of calcium or phosphate extracted from each bone.

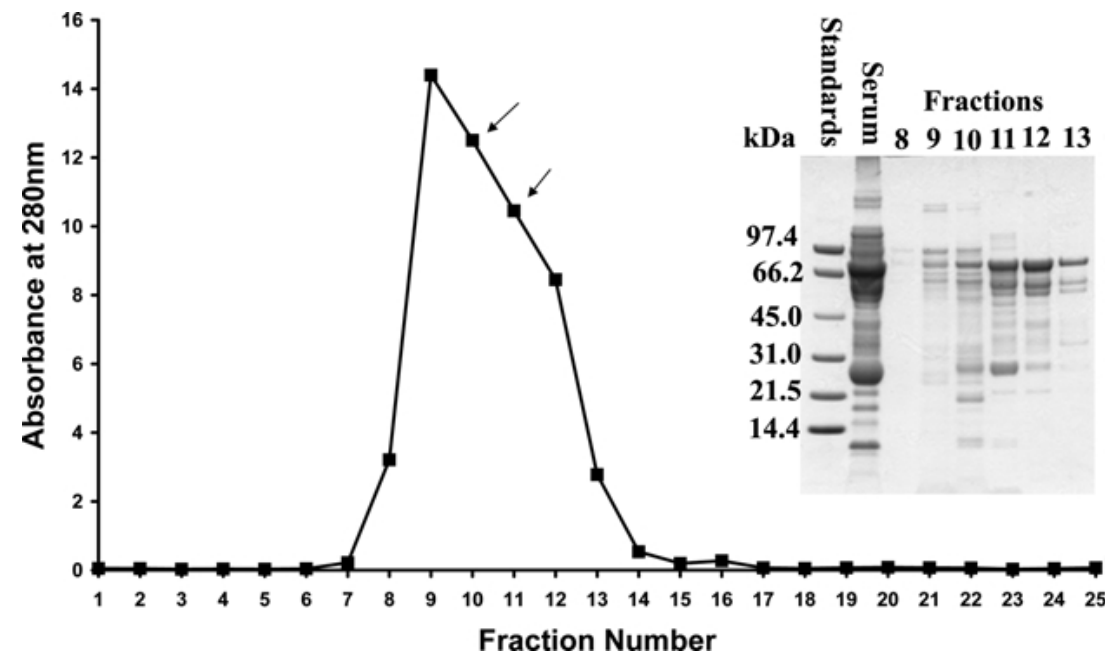

Fig. 2. Gel filtration evidence that the serum nucleator activity that initiates bone recalcification is a macromolecule: $\mathrm{A}_{280}$ chromatogram and SDS polyacrylamide gel electrophoresis of column fractions. The absorbance at $280 \mathrm{~nm}$ was measured for each $1 \mathrm{~mL}$ fraction, and $2 \mu \mathrm{L}$ of fractions $8-13$ were electrophoresed on a 4 $12 \%$ Bis-Tris polyacrylamide gel and stained with Coomassie brilliant blue. Arrows indicate the fractions that initiated calcification of a tibia, as seen in Figure 1. several higher molecular weight bands, $>50 \mathrm{kDa}$, as well as some lower molecular weight bands, $<30 \mathrm{kDa}$. This S-100 column with fish serum has been repeated with comparable results.

We used dialysis with MWCO membrane to confirm the observation that the serum calcifying activity is of high molecular weight. DMEM was used as the dialysis buffer since we know it to be a suitable buffer for calcification assays in vitro. Aliquots $(1.5 \mathrm{~mL})$ of rat or bony fish serum were dialyzed against DMEM using 50,000 MWCO dialysis tubing (see Materials and Methods). Figure 3 shows alizarin-stained tibias that have been incubated for 12 days in $15 \%$ and $5 \%$ dilu- tions of dialyzed rat and bony fish serum and of rat serum before dialysis. Even after exhaustive dialysis with a 50,000 MWCO membrane, activity was retained at both $15 \%$ and $5 \%$ dilutions of rat and bony fish serum. These data, along with the S-100 gel filtration results, indicate that bony fish have a high molecular weight serum nucleator just as seen previously in the rat [2].

\section{Calcification Activity in Shark Serum}

The serum of a cartilaginous fish, the leopard shark, was tested for the presence of calcification activity in the same manner as with the bony fish, hybrid striped bass, 


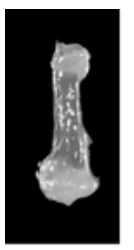

$15 \%$ Rat serum

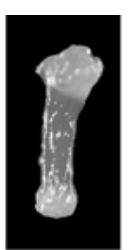

$5 \%$

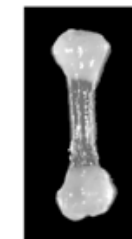

$15 \%$

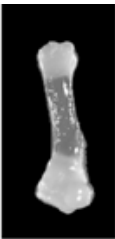

$5 \%$

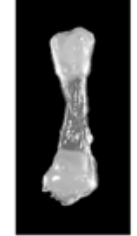

$15 \%$

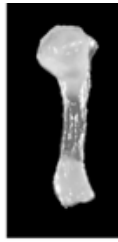

$5 \%$

Bony fish serum

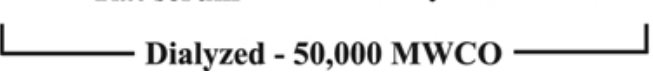

Fig. 3. Serum nucleator activity is retained after dialysis of rat and bony fish serum with a 50,000 MWCO membrane. Samples of rat and bony fish serum were each dialyzed in 50,000 MWCO membrane vs. DMEM for 2 days (see Materials and Methods). After incubation for 12 days in $15 \%$ and $5 \%$ dilu- tions of rat serum or dialyzed rat or bony fish serum, tibias were stained with alizarin red. A tibia incubated in DMEM without serum is shown as a negative control. This experiment shows that serum mineral nucleator activity was retained after dialysis using a high MWCO membrane.

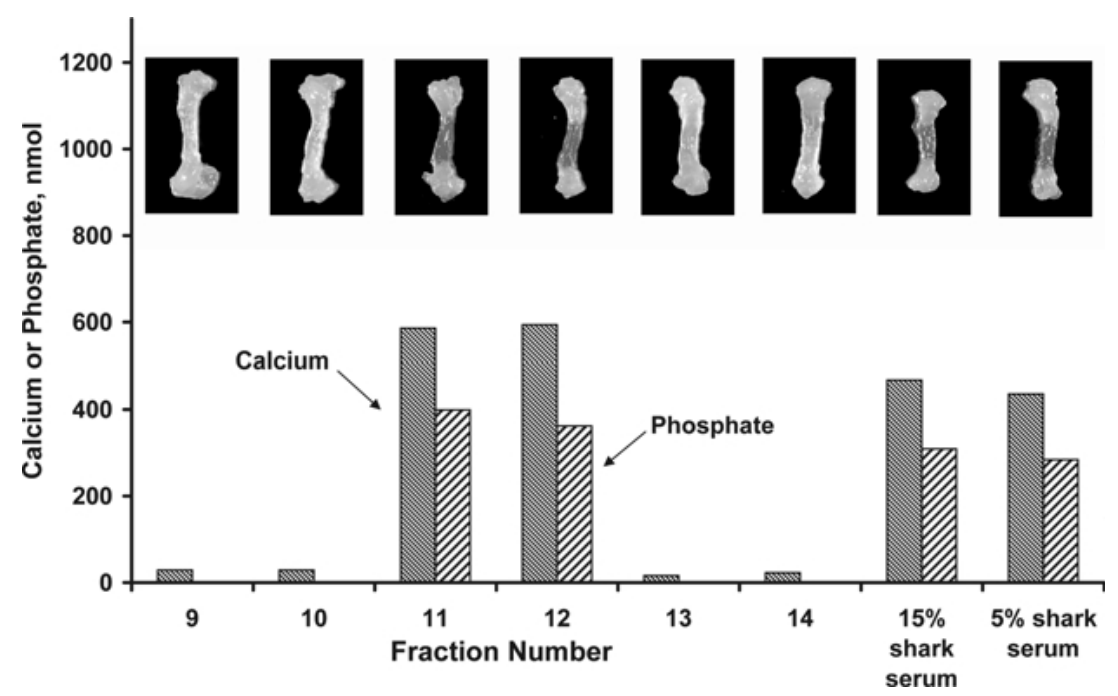

Fig. 4. Serum nucleator activity in Sephacryl S-100 column fractions of shark serum and in dilutions of shark serum in DMEM. Shark serum was either diluted into DMEM at $15 \%$ or $5 \%$ in $1 \mathrm{~mL}$ volumes or run over a Sephacryl S-100 column with $1 \mathrm{~mL}$ fractions collected (see Materials and Methods). A demineralized newborn rat tibia was incubated in each of these dilutions or fractions for 12 days at $37^{\circ} \mathrm{C}, 5 \% \mathrm{CO}_{2}$. Photographs at the top show alizarin red-stained tibias after the 12day incubation. Only tibias from fractions 11 and 12, as well as

tibias with serum diluted into DMEM, stained positive for calcification. The same tibias were extracted with $1 \mathrm{~mL}$ of 150 $\mathrm{mM} \mathrm{HCl}$ and assayed for calcium and phosphate. Bars indicate the level of calcium or phosphate extracted from each bone. In a repeat experiment, calcification of demineralized tibias was again restricted to fractions 11 and 12 of the Sephacryl S-100 column, and calcification of tibias was also observed in DMEM containing $5 \%$ and $15 \%$ shark serum but not in DMEM alone.

above. While sharks have a cartilaginous skeleton and lack true bone, they do have calcified teeth and vertebrae, suggesting that serum nucleator activity may be present $[4,5]$. The leopard shark serum samples contained $3.3 \mathrm{mM}$ total calcium and $1.4 \mathrm{mM}$ ionic phosphate. Figure 4 shows the results obtained for representative tibias incubated for 12 days in DMEM with $15 \%$ or $5 \%$ leopard shark serum. As seen with fish serum, the leopard shark serum was able to remineralize a tibia as determined by alizarin red staining and by analysis of calcium and phosphate levels. Shark serum $(1.5 \%)$ was also able to remineralize a tibia but to a more modest extent. Similar remineralization was also observed in demineralized tibias incubated for 12 days in
DMEM containing 15\% and 5\% blue shark (P. glauca) serum (data not shown).

Figure 5 shows the $\mathrm{A}_{280}$ chromatogram for a shark serum S-100 column, with arrows indicating the fractions that were able to mineralize a tibia (see Fig. 4). As in the bony fish, shark serum nucleator activity is localized to only two fractions, 11 and 12 . These gel filtration experiments were repeated with comparable results. Two microliters of each of the fractions across the protein peak were electrophoresed on a $4-12 \%$ BisTris polyacrylamide gel and stained with Coomassie brilliant blue. A $2 \mu \mathrm{L}$ sample volume is shown to better compare with bony fish (Fig. 2) and rat serum [2]. As seen in Figure 5, the molecular weight of proteins elut- 


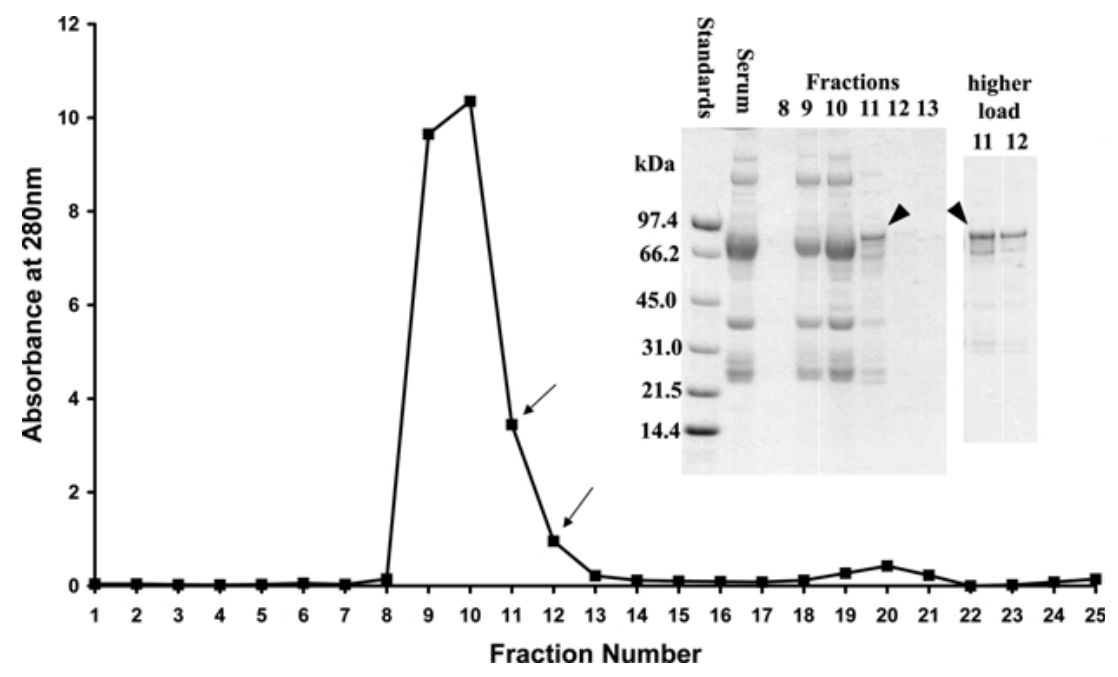

Fig. 5. $A_{280}$ chromatogram of shark Sephacryl S-100 column and polyacrylamide gel electrophoresis of column fractions. Absorbance at $280 \mathrm{~nm}$ was measured for each $1 \mathrm{~mL}$ fraction of the column. Two microliters of fractions $8-13$ were electrophoresed on a 4-12\% Bis-Tris polyacrylamide gel and stained with Coomassie brilliant blue. To better observe faint bands in fractions 11 and $12,20 \mu \mathrm{g}$ of these samples were run on a second gel; these lanes are shown to the right of the gel described above. Arrows indicate the fractions that initiated calcification of a tibia, as seen in Figure 4. Arrowheads indicate the most prominent band in fractions 11 and 12 that was sequenced and tentatively identified as shark transferrin. ing from these fractions is largely between 25 and 80 $\mathrm{kDa}$. Bands in fraction 12 are difficult to see at this protein load and were rerun, along with fraction 11 , with a load sufficient to achieve $20 \mu \mathrm{g}$ of protein for each lane. Two bands above $66 \mathrm{kDa}$ are present in both fractions 11 and 12 . The most prominent band, indicated with arrowheads, was $\mathrm{N}$-terminally sequenced, and the first 14 amino acid residues were identified as TDPPIKWXTVSTQE. A search of the National Center of Biotechnology Information protein sequence database reveals that this $\mathrm{N}$-terminal sequence has homology with mouse transferrin. Six residues are exactly conserved by position, with several conservative substitutions, and the band migrates with a molecular mass corresponding well with mouse transferrin, an $\sim 80 \mathrm{kDa}$ serum glycoprotein secreted by the liver and involved in iron metabolism. We conclude that this band is highly likely to be shark transferrin.

\section{Calcification Activity in Serum from Jawless Fish: Lamprey and Hagfish}

We next wanted to test the serum of vertebrate species that lacked any calcified structures, the lamprey and hagfish, both jawless fish. Demineralized newborn rat tibias were incubated for 12 days at $37^{\circ} \mathrm{C}$ in Pacific lamprey serum, in DMEM containing $15 \%$ or $5 \%$ lamprey serum, or in DMEM alone. Alizarin red staining of the tibias for calcification showed that no tibia was calcified (data not shown). A $1 \mathrm{~mL}$ aliquot of lamprey serum was chromatographed over an S-100 gel filtration column, and the fractions were tested for nucleator activity. Alizarin red staining could be seen in the growth plate region of tibias incubated in fractions 1114, though no fraction calcified the midshaft of the tibia (data not shown). This mineralization pattern is similar to that seen in dialyzed lamprey serum samples (see Fig. 6). This gel filtration experiment was repeated, and it was confirmed that discernable alizarin staining was present in one or both of the growth plates of the tibias incubated in fractions 11-14, while no fraction showed calcification of a tibial midshaft.

The total calcium and inorganic phosphate levels in lamprey serum are low compared to rat and bony fish (Table 1). Therefore, each serum sample was first dialyzed against DMEM in 3,500 MWCO dialysis tubing in order to establish comparable ionic environments for all species. These dialyzed serum samples were tested for calcification activity at $100 \%$ and 10\% in DMEM (see Materials and Methods). Demineralized rat tibias incubated in dialyzed rat or bony fish serum calcify in 12 days, as seen by alizarin red staining and by analysis for calcium and phosphate (Fig. 6). Dialyzed lamprey serum was able to calcify the growth plates but not the midshaft of the tibia, a result also seen in the gel filtration fractions of lamprey serum. Tibias incubated in DMEM dialysis buffer alone did not become calcified.

Pacific hagfish serum was similarly tested for nucleator activity by dilutions in DMEM and by gel filtration over an S-100 column to test fractions for calcification activity. No serum dilution in DMEM or fraction from the column showed any mineral nucleating activity over the course of a 12-day incubation. Sufficient serum samples were not available to employ low molecular weight cut-off dialysis.

\section{Calcification Activity in Invertebrate Sera}

Neat sera from each of the three invertebrates examined, or dilutions of these sera (15\% or 5\%) into phosphateboosted DMEM, were not able to mineralize a tibia in 12 days (data not shown). When each invertebrate serum was size-fractionated over an S-100 gel filtration column equilibrated with phosphate-boosted DMEM, no fraction was able to mineralize a tibia (data not shown). Sera from the sea worm, crab, and sea urchin all 


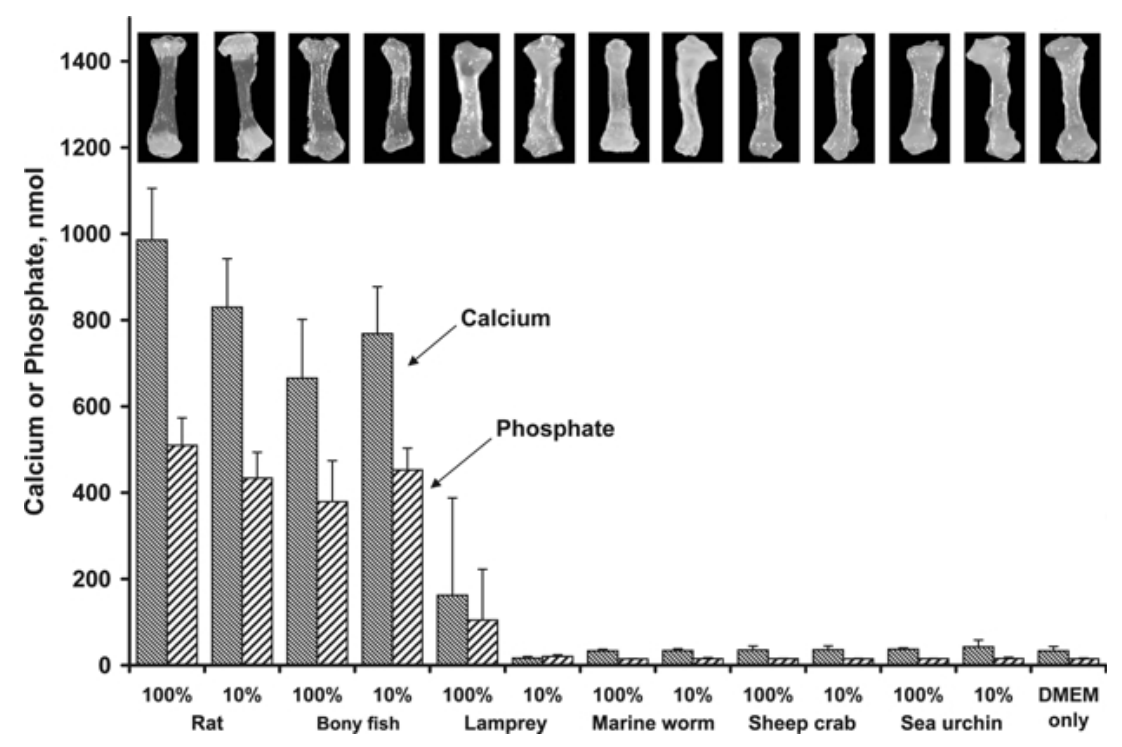

Fig. 6. Alizarin red-stained tibias and calcium and phosphate extracts after incubation in dialyzed vertebrate or invertebrate sera of the species indicated. Sera were dialyzed for 2 days against DMEM in order to normalize calcium and phosphate. Demineralized tibias were incubated in dialyzed serum directly $(100 \%)$ or in serum diluted into DMEM (10\%) for 12 days at $37^{\circ} \mathrm{C}, 5 \% \mathrm{CO}_{2}$. After incubation, tibias were stained with alizarin red (top). Calcium and phosphate were extracted with acid and measured quantitatively. Error bar represents $1 \mathrm{SD}$ above the mean, $n=3$.

have calcium and phosphate levels in their blood similar to that found in seawater, $\sim 10 \mathrm{mM} \mathrm{Ca}$ and $<0.5 \mathrm{mM}$ $\mathrm{PO}_{4}$ (see Table 1); and it may be unreasonable to expect mineralization by neat serum when little or no phosphate is available. To maximize the potential of mineralization events, we concluded that invertebrate sera would have to be tested with ionic calcium and phosphate concentrations that are closer to those seen in vertebrates. In order to accomplish this, we dialyzed the invertebrates' sera in 3,500 MWCO tubing against phosphate-boosted DMEM, as was done with vertebrate sera above. Table 1 presents the results of the dialysis and shows that we were able to bring the total calcium and phosphate values to the level found in DMEM and, therefore, close to those of the vertebrates. It should be noted that the total calcium and phosphate levels after dialysis in the invertebrates were slightly lower than those of the vertebrates, but we have no data on the presence or absence of calcium binding proteins in the serum of the invertebrates. (Approximately half of the calcium in the serum of the vertebrates is bound to calcium binding proteins such as albumin, so the ionic calcium in the serum of vertebrates is closer to $1 \mathrm{mM}$.) Figure 6 shows that, even after this dialysis step, no invertebrate samples were able to mineralize a tibia at either $100 \%$ or $10 \%$ dialyzed serum, indicating a lack of serum nucleator activity.

\section{Discussion}

Bony Fish and Shark Serum Contain One or More Factors that Initiate Bone Mineralization

The experiments in this study were designed to test the hypothesis that any vertebrate with a calcified skeleton will have a nucleator of bone mineralization in its serum similar to the nucleator previously found in rat and bovine serum [1,2]. The first experiments examined the ability of serum from bony fish and sharks to recalcify demineralized newborn rat tibias using assay procedures employed in previous investigations of the serum nucleator activity in bovine and rat serum. (While the shark, a cartilaginous fish, does not have true bone, it does have several calcified structures, including enamel, dentine, and calcified cartilage, with a calcium phosphate mineral phase indistinguishable from the mineral phase in bony vertebrates [5].) The results of these studies showed that demineralized tibias recalcify when incubated in DMEM containing as little as $1.5 \%$ fish or shark serum but do not recalcify when incubated in the same DMEM solution alone. Since such low concentrations of serum have a negligible effect on the ionic milieu of DMEM, the most reasonable explanation for these observations is that bony fish and shark serum both contain potent calcifying activity. If this interpretation is correct, the minimum amount of serum that must be added to DMEM in order to induce the recalcification of demineralized bone should provide some measure of the amount of calcification activity in the serum of different species. Bony fish, rat, shark, and bovine serum all induce calcification at $1.5 \%$ serum but not at $0.5 \%$, so each appears to have a comparable level of calcifying activity.

The next experiments examined the apparent molecular mass of the serum nucleator activity found in bony fish and shark serum, using the same procedures previously employed to determine the apparent molecular mass of the serum nucleator activity in rat serum [2]. In these experiments, serum was gel-filtered over an S-100 column equilibrated with DMEM in order to fractionate serum proteins by size and to replace the low molecular weight ionic constituents of serum with the ionic milieu of DMEM. The results of these experiments show that protein-containing fractions of comparable molecular 
weight recalcify demineralized tibias regardless of whether the serum is from bony fish, shark, or rat. In contrast, demineralized tibias did not recalcify when incubated in adjacent protein-containing fractions, in other effluent fractions, or in the column buffer itself.

Is it possible that serum does not actually initiate calcification of demineralized tibias but, instead, merely supplies the calcium phosphate ion product needed to foster the growth of apatite microcrystals remaining in the bone matrix after demineralization? There are several reasons to believe that the answer to this question is "no." (1) It is unlikely that a calcium phosphate mineral phase remains in tibias demineralized by these procedures since calcium and phosphate can no longer be detected in these tibias by chemical analysis, von Kossa staining, or alizarin red staining [2]. In addition, increasing demineralization times by several fold has no effect on the ability of the demineralized tibias to be recalcified in serum [2]. (2) The ion product of normal vertebrate serum is comparable to the $3.6 \mathrm{mM}^{2}$ ion product of the phosphate-boosted DMEM used in the present studies. If microcrystals grow in serum because of the calcium phosphate ion product of serum, these crystals should also grow in DMEM. However, in the numerous control experiments carried out over the 3-year period during which this and earlier studies were conducted, we have never seen any evidence of calcification in demineralized tibias incubated in DMEM alone for periods of 6 to as much as 12 days. (In contrast, the microcrystals introduced by incubation of demineralized tibias in serum for 12 hours did increase in mass by over 100-fold during a subsequent 5-day incubation in DMEM in the absence of serum [2].) (3) Demineralized tibias only recalcify in DMEM-containing serum, and the amount of serum can be as little as $1.5 \%$. This observation cannot be explained by an increase in solution ion product due to the addition of such small amounts of serum; not only are the ion products of serum and DMEM essentially identical but the amount of serum added to DMEM is far too small to affect the ionic composition of the solution. The most likely explanation for the fact that demineralized tibias recalcify when incubated in DMEM containing $1.5 \%$ bony fish or shark serum but not when incubated in DMEM alone is that both sera contain potent calcifying activity.

The observation that both bony fish and shark sera share with rat and bovine sera activity that nucleates the mineralization of the type I collagen matrix of bone is consistent with the nature of the continuum between calcified structures and the body fluid [6, 7]. The calcified structures of the endoskeleton derive their composition from the ionic environment of blood, and all bony vertebrates and elasmobranchs (sharks) have an ionic composition in their blood suitable for calcium phosphate mineral formation [5]. One hypothesis is that the serum nucleator is locally produced near mineralizing structures and, due to the continuum between calcified structures and blood, the nucleator necessarily escapes into the circulation, where it may be less active due to circulating mineral inhibitors such as fetuin and matrix Gla protein [8-11]. An alternative hypothesis is that the serum nucleator is produced outside of calcified tissues, released into the circulation in an inactive state, and activated at mineralization sites.

Invertebrate Sera Do Not Contain a Nucleator of Bone Mineralization

We employed several techniques in order to reveal any possible serum mineral nucleating activity in the sera of three different invertebrates. We found no mineral nucleating activity in any of these sera under any conditions tested. The most direct methods, diluting sera into DMEM or separating sera over an S-100 gel filtration column, showed no calcification of a tibia at any serum concentration or elution position. Invertebrate serum is a body fluid which is isotonic to seawater and contains little inorganic phosphate, and the potential for calcium phosphate mineralization of a tibia could be predicted to be very small. We therefore asked the question "If invertebrate sera are introduced to an ionic environment like that in a vertebrate, will any invertebrate sera demonstrate mineral nucleating activity?" To this end, we employed low MWCO dialysis of invertebrate and vertebrate sera against DMEM in order to normalize the ionic environment between them. Incubation of a demineralized tibia in either $100 \%$ dialyzed invertebrate serum or invertebrate serum diluted to $10 \%$ in DMEM for up to 12 days never revealed mineral nucleating activity. Rat and bony fish serum dialyzed under the same conditions readily calcified a demineralized tibia under the same incubation conditions. Repeated failure to find mineral nucleating activity in invertebrate sera from the three species tested strongly supports our hypothesis that invertebrates that lack a calcium phosphate endoskeleton also lack a serum nucleator of mineralization.

Lamprey Serum May Demonstrate a Unique Potential for Bone Mineralization

While the serum of a hagfish (a nonbony vertebrate with no calcified structures) fails to show mineral nucleating activity when diluted into DMEM or in fractions of an S-100 gel filtration column, the lamprey, a related jawless fish, shows a different result. As was found with hagfish and invertebrate sera, lamprey serum failed to mineralize a tibia in dilutions of up to $15 \%$ in DMEM. However, lamprey serum fractionated over an S-100 column revealed calcification activity in fractions 11-14. 
Tibias incubated in these fractions stained with alizarin red exclusively in the growth plate region but not in the midshaft. Tibias incubated in $100 \%$ dialyzed lamprey serum also stained with alizarin red in the growth plate (Fig. 6).

At this time, it is unclear whether the location of the mineral at the growth plates is associated with the type I collagen matrix of bone, the same collagen matrix of the midshaft of the tibia, or if it is associated with the type II collagen matrix of the growth plate cartilage. This alizarin red staining pattern may be a unique artifact of incubating a tibia in lamprey serum under these conditions. Alternatively, it may be indicative of a real and very specific nucleating activity that differs in its specificity compared to other vertebrate sera and may reveal a potential for the calcification of as yet undiscovered structures in the lamprey.

\section{Serum Nucleator Activity Is Evolutionarily Conserved among} All Vertebrates with a Calcified Endoskeleton

In this study, we provide compelling evidence that all vertebrate species with a calcified skeleton have serum mineral nucleating activity. By dilution of serum into DMEM, the potencies of the serum activity are comparable. Gel filtration chromatography shows that the apparent molecular mass of the serum activity in each species is remarkably similar. After repeated attempts using multiple techniques, we found no evidence of similar activity in any of the invertebrate sera tested.

Whether the serum nucleator originates outside of mineralized structures or is produced locally, the continuum between the body fluid and calcified structures requires that the potential for calcification not be specific only to those structures that are mineralized. Investigations continue in order to better understand and identify the serum nucleator and how it is regulated. Understanding how serum calcification activity is controlled, by regulating the nucleator, the mineral inhibitors, or both, may shed light on the mechanism of normal mineralization and on the evolution of a bony endoskeleton in vertebrates.
Acknowledgments. We are grateful to the following people for their assistance: Jason Stannard and Mike McNair (Kent SeaTech Corporation, San Diego, CA) for hybrid striped bass blood; Dr. Matthew G. Mesa (U.S. Geological Survey, Columbia River Research Laboratory, Cook, WA), and David Close (laboratory of Dr. Wei Ming Li, Michigan State Univeristy, East Lansing, MI) for Pacific lamprey serum; Dr. Meredith Gould (University of California, San Diego) for marine worm serum; Eddie Kisfaludy (SIO, La Jolla, CA) for acquiring and housing hagfish, sharks, crab and sea urchins; Dr. Russell Doolittle (University of California-San Diego) for helpful discussions; and Matthew Williamson for protein sequencing and critical review of the manuscript. This work was supported in part by grant HL-58090 from the National Heart, Lung, and Blood Institute of the NIH.

\section{References}

1. Hamlin NJ, Price PA (2004) Mineralization of decalcified bone occurs under cell culture conditions and requires bovine serum but not cells. Calcif Tissue Int 75:231-242

2. Price PA, June HH, Hamlin NJ, Williamson MK (2004) Evidence for a serum factor that initiates the re-calcification of demineralized bone. J Biol Chem 279:19169-19180

3. Chen PS, Toribara TY, Warner H (1956) Microdetermination of phosphorus. Anal Chem 28:1756-1758

4. Applegate SP (1967) A survey of shark hard parts. In: Gilbert PW, Mathewson RF, Rall DP (eds), Sharks, Skates, and Rays. Johns Hopkins Press, Baltimore, pp 37-67

5. Urist MR (1961) Calcium and phosphorus in the blood and skeleton of the Elasmobranchii. Endocrinology 69:778-801

6. Parfitt AM (2000) The mechanism of coupling: a role for the vasculature. Bone 26:319-323

7. Urist MR (1962) The bone-body continuum: calcium and phosphorus in the skeleton and blood of extinct and living vertebrates. Perspect Biol Med 6:75-115

8. Luo G, Ducy P, McKee MD, Pinero GJ, Loyer E, Behringer RR, Karsenty G (1997) Spontaneous calcification of arteries and cartilage in mice lacking matrix Gla protein. Nature 386:78-81

9. Price PA, Faus SA, Williamson MK (1998) Warfarin causes rapid calcification of the elastic lamellae in rat arteries and heart valves. Arterioscler Thromb Vasc Biol 18:1400-1407

10. Price PA, Lim JE (2003) The inhibition of calcium phosphate precipitation by fetuin is accompanied by the formation of a fetuin-mineral complex. J Biol Chem 278:22144-22152

11. Schinke T, Amendt C, Trindl A, Poschke O, Muller-Esterl W, Jahnen-Dechent W (1996) The serum protein alpha 2HS glycoprotein/fetuin inhibits apatite formation in vitro and in mineralizing calvaria cells. J Biol Chem 271:2078920796 